\title{
Tenolysis rate after zone 2 flexor tendon repairs
}

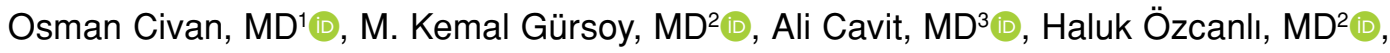 \\ M. Nazım Karalezli, MD ${ }^{4}$ (우 \\ ${ }^{1}$ Department of Orthopedics, Elmalı State Hospital, Antalya, Turkey \\ ${ }^{2}$ Department of Orthopedics, Akdeniz University Faculty of Medicine Antalya, Turkey \\ ${ }^{3}$ Department of Orthopedics, Uludağ University Faculty of Medicine Bursa, Turkey \\ ${ }^{4}$ Department of Orthopedics, Sıtkı Koçman University Faculty of Medicine Mugla, Turkey
}

Tendon adhesion to surrounding tissues after tendon repair, which is difficult to prevent in clinical practice, is the most common complication reported after tendon repair. ${ }^{[1]}$ Thus, reducing the incidence of adhesion after tendon repair without affecting tendon healing has become a popular research focus. New surgical and rehabilitation techniques are improving the results while an unanimity for the best method has not been obtained.

Tendon motion after tendon repair is important to avoid adhesions. Depending on the tendon repair strength, early passive or active flexion exercises may start immediately after the repair. Tendon gapping during or after the repair may deteriorate the results. The peripheral sutures serve to tidy up the repair site and prevent gapping. ${ }^{[2]}$ However, a suture exposure due to complex peripheral suture may lead to adhesion formation and increase gliding resistance during early active motion. ${ }^{[3]}$

Venting pulleys may also decrease the adhesion rate after flexor tendon repair. On the contrary to traditional knowledge about preserving A4 pulley, some authors recommend venting A4 pulley to

Received: October 08, 2019

Accepted: December 18, 2019

Published online: June 18, 2020

Correspondence: Osman Civan, MD. Elmalı Devlet Hastanesi Ortopedi ve Travmatoloji Kliniği, 07716 Elmall, Antalya, Türkiye.

E-mail: civanosman@gmail.com

Doi: $10.5606 /$ ehc. 2020.71752

Citation: Civan O, Gürsoy MK, Cavit A, Özcanlı H, Karalezli MN. Tenolysis rate after zone 2 flexor tendon repairs. Jt Dis Relat Surg 2020;31(2):281-285.

\section{ABSTRACT}

Objectives: This study aims to evaluate the tenolysis rates of zone 2 flexor digitorum profundus (FDP) with flexor digitorum superficialis (FDS) tendon repairs using four-strand technique and early passive motion exercises.

Patients and methods: In this retrospective study, we performed zone 2 flexor tendon repairs in 149 patients ( 117 males, 32 females, mean age $33.3 \pm 12.9$ years; range, 13 to 72 years) ( 82 right and 67 left hands) between November 2014 and January 2019. A total of 194 FDP and FDS tendons were repaired primarily by using modified Kessler and Bunnell methods. Patients underwent pure passive motion protocols after surgery according to modified Duran's protocol. No active flexion components were added until postoperative fourth week.

Results: Twenty-three out of 149 patients and 28 out of 194 fingers $(14.43 \%)$ had tenolysis. There was no significant relationship between the number of operated fingers, gender, and tenolysis rate ( $\mathrm{p}=0.836, \mathrm{p}=0.584$, respectively).

Conclusion: The repair of the FDP with FDS tendon increases the tenolysis rate in zone 2 . The tenolysis rate does not change according to the number or distribution of injured fingers and gender of the patient.

Keywords: Adhesion, flexor tendon injury, flexor tenolysis, passive motion protocol, tenolysis, zone 2 .

facilitate zone 2 flexor tendon repair, while some recommend venting A2 pulley. ${ }^{[4-7]}$

Repairing flexor digitorum superficialis (FDS) tendon is also controversial. To restore FDS function, some surgeons prefer to repair FDS ruptures. According to Tang, ${ }^{[8]}$ it may be better to leave FDS tendon unrepaired to decrease adhesion rate because leaving the FDS tendon unrepaired is not detrimental to finger motion. In this study, we aimed to evaluate the tenolysis rates of zone 2 flexor digitorum profundus (FDP) with FDS tendon repairs 


\begin{tabular}{|c|c|c|c|}
\hline \multicolumn{4}{|c|}{$\begin{array}{l}\text { TABLE I } \\
\text { phic data of patients }\end{array}$} \\
\hline \multirow[b]{2}{*}{ Parameter } & \multicolumn{3}{|c|}{ Description } \\
\hline & $n$ & Mean $\pm S D$ & Range \\
\hline Age (year) & & $33.3 \pm 12.9$ & $13-72$ \\
\hline \multicolumn{4}{|l|}{ Gender } \\
\hline Male & 117 & & \\
\hline Female & 32 & & \\
\hline \multicolumn{4}{|c|}{ Dominant hand } \\
\hline Right & 82 & & \\
\hline Left & 67 & & \\
\hline
\end{tabular}

using four-strand technique and early passive motion exercises.

\section{PATIENTS AND METHODS}

In this retrospective study, we performed zone 2 flexor tendon repairs in 149 patients (117 males, 32 females, mean age $33.3 \pm 12.9$ years; range, 13 to 72 years) (82 right and 67 left hands) at Akdeniz University, Faculty of Medicine, Department of Orthopedics and Traumatology between November 2014 and January 2019 (Table I). Patients referred with zone 2 FDP and FDS complete divisions were included. Cases with: (i) complete or incomplete amputation, (ii) thumb injuries, (iii) replantations, (iv) revascularizations, $(v)$ FDS intact or unrepaired injuries, (vi) concomitant phalanx fractures, nerve, artery or any other injuries preventing early motion were excluded. The study was conducted in accordance with the principles of the Declaration of Helsinki.

A total of 194 FDP and FDS tendons were repaired primarily by using modified Kessler and Bunnell repair methods. All repairs were applied in the first 24 hours after injury by 3-0 polydioxanone monofilament absorbable sutures. Knots were placed inside the tendon surfaces. Running peripheral sutures were not used in the repair sites. In two cases, we added two and in two cases, we added three sparse running sutures laterally or palmarly. We applied midline A2 pulley venting in all cases and did not need venting of the A4 pulleys in any of the cases. We did not shorten any of the pulleys.

Patients underwent pure passive motion protocols after surgery according to modified Duran's protocol. We applied a dorsal protective cast (wrist in position from $0^{\circ}$ to $20^{\circ}$ flexion, metacarpophalangeal joints in $40-50^{\circ}$ flexion, interphalangeal joints allowed to get full extension position) at the end of the operation. We replaced the cast with splint in the first three days postoperatively and used it till the end of the fourth week. The passive range of motion (ROM) was started on the first postoperative day. No active flexion components were added until the postoperative fourth week. Splint was applied till the end of fourth week and then the active ROM was started. Patients started stretching their fingers to extension passively after sixth week. After eighth week, strengthening exercise was started and rehabilitation continued to postoperative $10^{\text {th }}$ to $12^{\text {th }}$ week.

The patients that these protocols could be applied, retrospectively evaluated about the details of the surgical procedures from the archiving system of the hospital (Mia-Med version 1.0.1.2808, Mia Technology AŞ, Ankara, Türkiye).

\section{Statistical analysis}

Statistical analysis was performed using the IBM SPSS version 23.0 software (IBM Corp., Armonk, NY, USA). The tenolysis rate and the association with gender and the operated number of fingers were compared statistically. The relationships between the operated number of fingers and the tenolysis rate and gender were evaluated using Fisher's exact test. A $p$ value of $<0.05$ was considered statistically significant.

\section{RESULTS}

None of the patients had any additional pathology. The distribution of the fingers is listed in Table II. Tenolysis was indicated if the injured fingers did

\begin{tabular}{|lcccccc|}
\multicolumn{7}{c|}{ TABLE II } \\
& Distribution of tenolysis and repair for each finger & & \\
& $2^{\text {nd }}$ Finger & $3^{\text {rd }}$ Finger & $4^{\text {th }}$ Finger & $5^{\text {th }}$ Finger & Total \\
\hline Tenolysis & 6 & 2 & 9 & 11 & 28 \\
Repair & 43 & 38 & 44 & 69 & 194 \\
Tenolysis/repair rate (\%) & 13.9 & 5.2 & 20.4 & 15.9 & 14.4 \\
\hline
\end{tabular}


not recover at least $40-50 \%$ of the normal range of interphalangeal joint active motion by six months postoperatively. All of our patients with less than $50 \%$ of motion recovery wanted to have tenolysis. Consequently, 23 out of 149 patients and 28 out of 194 fingers $(14.43 \%)$ had tenolysis. The distribution of tenolysis and repair for each finger is listed in Table II.
Of the 149 patients, 119 were operated for tendon injury of only one finger. Nineteen patients were operated for tendon injury of two fingers, nine for three fingers, and two for four fingers (Table III). A comparison of fingers in terms of the tenolysis rate did not reveal any significant relationship between the operated number of fingers and the tenolysis rate $(p=0.836)$. Despite the challenges in physical therapy

\begin{tabular}{|c|c|c|c|}
\hline \multicolumn{4}{|c|}{$\begin{array}{l}\text { TABLE III } \\
\text { Distribution of injured fingers and tenolysis for patients }\end{array}$} \\
\hline \multirow[b]{2}{*}{ Fingers } & \multicolumn{2}{|c|}{ Applied tenolysis (Number of the patients) } & \multirow{2}{*}{$\frac{\text { Number of the patients }}{\text { Total }}$} \\
\hline & No & Yes & \\
\hline \multicolumn{4}{|l|}{ Isolated $2^{\text {nd }}$ finger } \\
\hline Count & 28 & 6 & 34 \\
\hline Within fingers (\%) & 82.4 & 17.6 & 100.0 \\
\hline \multicolumn{4}{|l|}{ Isolated $3^{\text {rd }}$ finger } \\
\hline Count & 20 & 0 & 20 \\
\hline Within fingers (\%) & 100.0 & 0.0 & 100.0 \\
\hline \multicolumn{4}{|l|}{ Isolated $4^{\text {th }}$ finger } \\
\hline Count & 13 & 5 & 18 \\
\hline Within fingers (\%) & 72.2 & 27.8 & 100.0 \\
\hline \multicolumn{4}{|l|}{ Isolated $5^{\text {th }}$ finger } \\
\hline Count & 39 & 8 & 47 \\
\hline Within fingers (\%) & 83.0 & 17.0 & 100.0 \\
\hline \multicolumn{4}{|l|}{$2^{\text {nd }}-3^{\text {rd }}$ fingers } \\
\hline Count & 4 & 0 & 4 \\
\hline Within fingers (\%) & 100.0 & 0.0 & 100.0 \\
\hline \multicolumn{4}{|l|}{$3^{\text {rd }}-4^{\text {th }}$ fingers } \\
\hline Count & 2 & 0 & 2 \\
\hline Within fingers (\%) & 100.0 & 0.0 & 100.0 \\
\hline \multicolumn{4}{|l|}{$4^{\text {th }}-5^{\text {th }}$ fingers } \\
\hline Count & 11 & 2 & 13 \\
\hline Within fingers (\%) & 84.6 & 15.4 & 100.0 \\
\hline \multicolumn{4}{|l|}{$2^{\text {nd }}-3^{\text {rd }}-4^{\text {th }}$ fingers } \\
\hline Count & 2 & 0 & 2 \\
\hline Within fingers (\%) & 100.0 & 0.0 & 100.0 \\
\hline \multicolumn{4}{|l|}{$3^{\text {rd }}-4^{\text {th }}-5^{\text {th }}$ fingers } \\
\hline Count & 5 & 2 & 7 \\
\hline Within fingers (\%) & 71.4 & 28.6 & 100.0 \\
\hline \multicolumn{4}{|l|}{$2^{\text {nd }}-3^{\text {rd }}-4^{\text {th }}-5^{\text {th }}$ fingers } \\
\hline Count & 2 & 0 & 2 \\
\hline Within fingers (\%) & 100.0 & 0.0 & 100.0 \\
\hline \multicolumn{4}{|l|}{ Total } \\
\hline Count & 126 & 23 & 149 \\
\hline Within fingers (\%) & 84.6 & 15.4 & 100 \\
\hline
\end{tabular}


of multiple finger injuries, multiple tendon injuries did not have any effect on tenolysis rate. There was no statistically significant difference in terms of the tenolysis rate between genders $(p=0.584)$. The four fingers that were added two or three sparse running sutures did not require tenolysis in the follow-up period.

\section{DISCUSSION}

Tendon motion after tendon repair is important to avoid adhesions. To obtain a good motion and to prevent adhesion of the tendons, early motion is recommended which can be established with passive or active manner according to surgeons' choice. Despite the higher rate of ROM with early active motion, re-rupture rate of the flexor tendons after repair is approximately $5-9 \%$ and because of this considerably high re-rupture rate, some authors recommend early passive motion instead of active motion. ${ }^{[9-12]}$

Different tenolysis rates ranging from 1.7 to $24 \%$ have been reported for different rehabilitation protocols. ${ }^{[13,14]}$ In this study, early passive motion till fourth week was preferred to prevent re-rupture. ${ }^{[15]}$ However, our tenolysis rate of $14.4 \%$ showed that the adhesion rate was higher than early active motion protocols. ${ }^{[1,11,16-19]}$

Tendon gapping during or after the repair may deteriorate the results. The peripheral sutures serve to tidy up the repair site and prevent gapping. ${ }^{[2]}$ However, clinically, complex peripheral sutures are hard to perform, particularly on the dorsal aspect of the repaired tendon. Peripheral suture exposure may also lead to adhesion formation and increase gliding resistance during early active motion. ${ }^{[3]}$ The authors did not perform running peripheral sutures for the patients included in this study. As Tang ${ }^{[8]}$ reported that peripheral sutures can be rather sparse or even absent, we did not prefer to use epitendinous sutures. As Tang $^{[8]}$ reported that peripheral sutures can be rather sparse or even absent, we did not prefer to use epitendinous sutures since the multistrand core repairs were sufficient and peripheral sutures may lead to a risk of accelerated adhesion formation. In four cases, we added two or three sparse running sutures laterally or palmarly as recommended by Tang. ${ }^{[20]}$

A4 pulleys of the operated fingers were not needed to vent and were protected as much as possible although venting of A4 pulley was reported as not affecting the results. ${ }^{[8]}$ We applied midline A2 pulley venting in all cases and did not need venting of the A4 pulleys in any of the cases.
There is a large variability in the management of zone 2 flexor tendon injuries. Surgical technique, surgery material, postoperative immobilization, and rehabilitation protocol are changeable due to different écoles. ${ }^{[21]}$ We had a tendency to repair FDS tendon; however, we know that FDS tendon repair is not recommended by some authors because the passage of the retracted tendon stump under the narrow A4 pulley is often difficult, and some authors prefer to resect the FDS tendon. ${ }^{[17,22]}$ Despite the knowledge that the FDS tendon is one of the most likely causes of tendon adhesions, we included patients with repaired FDS tendons in cases of zone 2 lacerations in this study. It was due to provide equality for the evaluation of each case. We believe that this is one of the reasons for the higher tenolysis rate in our study.

This study has some limitations. First, our results were evaluated retrospectively and we only had one group precluding to compare the results to other techniques and rehabilitation protocols. We believe that further studies are needed to compare the results of different surgical and rehabilitation procedures.

In conclusion, the gold standard management of zone 2 flexor tendon repair and rehabilitation protocol is still controversial. Repair of FDS tendon with FDP increases the tenolysis rate and the tenolysis rate does not change according to the distribution or the number of injured fingers and gender of the patient.

\section{Declaration of conflicting interests}

The authors declared no conflicts of interest with respect to the authorship and/or publication of this article.

\section{Funding}

The authors received no financial support for the research and/or authorship of this article.

\section{REFERENCES}

1. Rigo IZ, Røkkum M. Predictors of outcome after primary flexor tendon repair in zone 1, 2 and 3. J Hand Surg Eur Vol 2016;41:793-801.

2. Tang JB. Flexor Tendon Injuries. Clin Plast Surg 2019;46:295306.

3. Pan ZJ, Xu YF, Pan L, Chen J. Zone 2 flexor tendon repairs using a tensioned strong core suture, sparse peripheral stitches and early active motion: results in 60 fingers. J Hand Surg Eur Vol 2019;44:361-6.

4. Moriya K, Yoshizu T, Maki Y, Tsubokawa N, Narisawa H, Endo N. Clinical outcomes of early active mobilization following flexor tendon repair using the six-strand technique: short- and long-term evaluations. J Hand Surg Eur Vol 2015;40:250-8.

5. Tang JB. Outcomes and evaluation of flexor tendon repair. Hand Clin 2013;29:251-9. 
6. Tang JB. Flexor tendon injury and reconstruction. In: Chang J, editor. Plastic Surgery. Vol. 6. 3rd ed. London: Elsevier Saunders; 2013. p. 178-209.

7. Tang JB. Release of the A4 pulley to facilitate zone II flexor tendon repair. J Hand Surg Am 2014;39:2300-7.

8. Tang JB. New Developments Are Improving Flexor Tendon Repair. Plast Reconstr Surg 2018;141:1427-37.

9. Chesney A, Chauhan A, Kattan A, Farrokhyar F, Thoma A. Systematic review of flexor tendon rehabilitation protocols in zone II of the hand. Plast Reconstr Surg 2011;127:1583-92.

10. Elliot D, Giesen T. Primary flexor tendon surgery: the search for a perfect result. Hand Clin 2013;29:191-206.

11. Frueh FS, Kunz VS, Gravestock IJ, Held L, Haefeli M, Giovanoli $\mathrm{P}$, et al. Primary flexor tendon repair in zones 1 and 2: early passive mobilization versus controlled active motion. J Hand Surg Am 2014;39:1344-50.

12. Small JO, Brennen MD, Colville J. Early active mobilisation following flexor tendon repair in zone 2. J Hand Surg Br 1989;14:383-91.

13. Quadlbauer S, Pezzei Ch, Jurkowitsch J, Reb P, Beer T, Leixnering M. Early Passive Movement in flexor tendon injuries of the hand. Arch Orthop Trauma Surg 2016;136:285-93.

14. Strickland JW, GlogovacSV. Digital function following flexor tendon repair in Zone II: A comparison of immobilization and controlled passive motion techniques. J Hand Surg Am 1980;5:537-43.

15. Atik OŞ. Is there something new and interesting in my article? Eklem Hastalik Cerrahisi 2019;30:69.

16. Dy CJ, Hernandez-Soria A, Ma Y, Roberts TR, Daluiski A. Complications after flexor tendon repair: a systematic review and meta-analysis. J Hand Surg Am 2012;37:543-51.

17. Giesen T, Reissner L, Besmens I, Politikou O, Calcagni $\mathrm{M}$. Flexor tendon repair in the hand with the M-Tang technique (without peripheral sutures), pulley division, and early active motion. J Hand Surg Eur Vol 2018;43:474-9.

18. Tang JB. Flexor tendon repair in zone 2C. J Hand Surg Br 1994;19:72-5.

19. Moriya K, Yoshizu T, Tsubokawa N, Narisawa H, Maki Y. Incidence of tenolysis and features of adhesions in the digital flexor tendons after multi-strand repair and early active motion. J Hand Surg Eur Vol 2019;44:354-60.

20. Tang JB. Recent evolutions in flexor tendon repairs and rehabilitation. J Hand Surg Eur Vol 2018;43:469-73.

21. Bigorre N, Delaquaize F, Degez F, Celerier S. Primary flexor tendons repair in zone 2: Current trends with GEMMSOR survey results. Hand Surg Rehabil 2018;37:281-8.

22. Zhao C, Amadio PC, Zobitz ME, An KN. Resection of the flexor digitorum superficialis reduces gliding resistance after zone II flexor digitorum profundus repair in vitro. J Hand Surg Am 2002;27:316-21. 